\title{
COMPOSIÇÃO QUÍMICA E MOBILIZAÇÃO DE RESERVAS EM SEMENTES DE SOJA DE ALTO E BAIXO VIGOR (1)
}

\author{
FERNANDO AUGUSTO HENNING $\left({ }^{*}\right)$; LILIANE MARCIA MERTZ $\left({ }^{2}\right)$; ELIAS ABRAHÃO JACOB \\ JUNIOR ( $\left.{ }^{2}\right)$; RONEI DORNELES MACHADO $\left({ }^{3}\right)$; GUILHERME FISS $\left({ }^{(3)}\right.$; PAULO DEJALMA ZIMMER $\left({ }^{4}\right)$
}

\begin{abstract}
RESUMO
O estudo dos efeitos do vigor das sementes sobre os estádios iniciais do desenvolvimento das plântulas de soja é importante, já que compreendem o período de estabelecimento da cultura. Sementes de baixo vigor podem provocar reduções na velocidade de emergência e na produção de biomassa seca de plântulas, podendo afetar o estabelecimento da cultura. Este estudo teve por objetivo quantificar os componentes químicos e avaliar a capacidade de mobilização de reservas, na germinação de sementes de soja de alto e baixo vigor. Foram utilizadas três cultivares: BRS 243RR, BRS 246RR e CD 219RR. A caracterização do vigor foi por meio do teste de envelhecimento acelerado. Para determinação da composição química das sementes, foram quantificados os teores de proteínas, amido e açúcar solúvel, além da atividade da isoenzima alfa amilase. A capacidade de mobilização das reservas na germinação foi avaliada por meio da massa seca e do comprimento das plântulas. De acordo com os resultados desse trabalho, em sementes mais vigorosas há maiores conteúdos de proteínas solúveis, amido e açúcares solúveis, bem como maior capacidade de mobilização de reservas na germinação, resultando em plântulas de soja com melhor desempenho inicial.
\end{abstract}

Palavras-chave: Glycine max, proteínas, açúcares, massa seca.

\section{ABSTRACT \\ CHEMICAL COMPOSITION AND RESERVE MOBILIZATION IN SOYBEAN SEEDS WITH HIGH AND LOW VIGOR}

The study of vigour effect on the initial stages of soybean seeds development is important, once it includes the period of crop establishment. Seeds with low vigour may result in reduction of emergence rate and dry matter production, which may affect the crop establishment. The aims of this study were to quantify chemical components and to evaluate the capacity of seed reserve mobilization in germination of soybean seeds with high and low vigour. Three cultivars, BRS 243RR, BRS 246RR and CD 219RR were studied. The characterization of seed vigour was performed by the accelerated aging test. To determine seed chemical composition, soluble sugar, starch and soluble protein were quantified; in addition alpha amylase isoenzyme activity was also evaluated. The capacity of seed reserve mobilization during germination was evaluated by seedling dry matter and length. According to the results of this study, high vigour soybean seeds exhibit higher content of soluble proteins, starch and soluble sugars. Besides, they showed higher capacity of seed reserve mobilization during germination, resulting in a better performance for seedlings development.

Key-words: Glycine max, proteins, sugars, dry matter.

(1) Recebido para publicação em 30 de dezembro de 2008 e aceito em 26 de janeiro de 2010.

(2) Alunos do Programa de Pós-Graduação em Ciência e Tecnologia de Sementes, Universidade Federal de Pelotas (UFPel), Faculdade de Agronomia Eliseu Maciel, Departamento de Fitotecnia, Caixa Postal 354, 96010-900 Pelotas (RS). E-mail: fernandohenning@yahoo.com.br $\left({ }^{*}\right)$ Autor correspondente.

(3) Bolsista de Iniciação Científica CNPq.

(4) Departamento de Fitotecnia, UFPel, FAEM, Pelotas (RS). 


\section{INTRODUÇÃO}

Sob o aspecto bioquímico, o vigor envolve biossíntese de energia e compostos metabólicos, tais como proteínas, ácidos nucleicos, carboidratos e lipídeos, associados com a atividade celular, integridade das membranas celulares e com transporte e utilização das substâncias de reserva (AOSA, 1983). Segundo CARVALHO e NAKAGAWA (2000), tanto o vigor quanto o potencial de armazenamento das sementes são influenciadas pelos teores dos compostos presentes e, de modo geral, quanto maior o teor de reservas nas sementes, maior será o vigor das plântulas originadas.

Em sementes com baixo vigor pode haver reduções na velocidade de emergência, na produção de biomassa seca e nas taxas de crescimento das plantas, podendo afetar o estabelecimento da cultura, seu desempenho ao longo do ciclo e produtividade final (SCHUCH et al., 2000; Melo et al., 2006). Além disso, em lotes de sementes com menor vigor, há maior variação na sua composição, e consequentemente maior desuniformidade e menor velocidade na emergência. SCHUCH et al. (1999) verificaram que a redução do vigor em sementes de aveia aumentou o tempo médio necessário para a protrusão das radículas, bem como reduziu o número médio de radículas emitidas por dia. A maior velocidade na emergência e a produção de plântulas com maior tamanho podem proporcionar às plantas provenientes das sementes vigorosas uma vantagem inicial no aproveitamento de água, luz e nutrientes.

A mobilização de reservas em embriões de sementes de diversas espécies tem sido estudada por diferentes autores. Segundo ZiEgLER (1995), os carboidratos, lipídios e proteínas de reserva são utilizados na formação de componentes estruturais durante o crescimento da plântula. BEWLEY e BLACK (1994) afirmam que carboidratos pré-formados na semente servem como substrato da respiração durante o período pré-germinativo, sendo estes mesmos resultados confirmados por BuCKERIDGE et al. (1995) em sementes de Dimorphandra mollis.

O estudo dos efeitos do vigor das sementes sobre os estádios iniciais do desenvolvimento das plantas de soja é importante, já que compreendem o período de estabelecimento da cultura. O crescimento inicial precoce pode resultar em maior captura de luz pelas folhas, fazendo com que o índice de área foliar máximo seja atingido mais rapidamente (SIDDIQUE et al., 1990). Além disso, proporciona maior e mais rápido sombreamento da superfície do solo, ocorrendo desta forma, menor evaporação de água do solo, a qual pode ser aproveitada na transpiração e no crescimento das plantas. Aliado a isso, plantas com tamanho inicial e taxas de crescimento maiores, possuem elevada capacidade competitiva, proporcionando o fechamento mais rápido dos espaços entre as linhas e favorecendo o controle das plantas daninhas.

Este estudo teve por objetivo quantificar os componentes químicos e avaliar a capacidade de mobilização de reservas, na germinação de sementes de soja de alto e baixo vigor.

\section{MATERIAL E MÉTODOS}

Utilizaram-se sementes de três cultivares de soja, BRS 243RR, BRS 246RR e CD 219RR, provenientes de lotes de alto e baixo vigor. A avaliação da qualidade fisiológica e a caracterização do vigor das sementes foram feitas através dos testes de germinação e envelhecimento acelerado. A capacidade de mobilização de reservas das sementes durante a germinação foi determinada pelas avaliações de comprimento e de massa seca das plântulas e de cotilédones. Além disso, foi quantificado a massa de mil sementes e os componentes de reserva como proteínas solúveis, amido, açúcares solúveis e a expressão da isoenzima alfa amilase.

\section{Desempenho fisiológico e mobilização de reservas das sementes}

Germinação: foram utilizadas três repetições de 200 sementes semeadas em rolos de papel toalha Germitest (com 50 sementes por rolo), umedecidos e colocados em germinador à temperatura constante $\left(25^{\circ} \mathrm{C}\right)$. A avaliação foi realizada no sétimo dia após a semeadura seguindo as prescrições das Regras para Análise de Sementes (BRASIL, 1992), computando-se apenas as plântulas normais. Os resultados foram apresentados em porcentagem de germinação.

Envelhecimento acelerado: para realizar o teste de envelhecimento acelerado, utilizou-se o método descrito por KRZYZANOWSKI et al. (1999), com três repetições de 200 sementes, dispostas sobre uma bandeja de tela de arame galvanizado, fixado no interior de caixas plásticas (gerbox) as quais continham $40 \mathrm{~mL}$ de água destilada. As amostras foram incubadas em câmaras de germinação do tipo BOD, à temperatura constante de 41 ${ }^{\circ} \mathrm{C}$ por 48 horas. Transcorrido esse período, as sementes foram colocadas para germinar seguindo os mesmos procedimentos utilizados no teste de germinação. Os resultados foram expressos em porcentagem.

Comprimento de plântulas: para a avaliação do comprimento de plântulas foram utilizadas três repetições de 60 sementes para cada cultivar. As sementes foram colocadas para germinar à temperatura de $25{ }^{\circ} \mathrm{C}$ utilizando como substrato rolo de papel germitest umedecido. As avaliações foram realizadas aos sete dias após a semeadura, medindo-se o comprimento total de plântulas. Os resultados foram expressos em comprimento médio de plântulas em centímetros. 
Massa seca de plântulas e dos cotilédones: as plântulas de cada repetição, resultante da avaliação do teste de comprimento de plântulas, foram separadas e, com auxílio de um bisturi, removeram-se os cotilédones. Em seguida, os cotilédones e as plântulas foram acondicionados em sacos de papel e colocados para secar em estufa com circulação de ar a $70^{\circ} \mathrm{C}$, durante 24 horas. Após este período, as amostras foram retiradas da estufa, colocadas em dessecador e em seguida pesadas, determinando-se a massa seca total das plântulas e dos cotilédones da repetição, sendo os resultados expressos em mg/plântula e mg/cotilédone (NAKAGAWA, 1999).

Massa de mil sementes: o teste foi realizado de acordo com as Regras para análise de sementes (BRASIL, 1992), utilizando-se três repetições com oito subamostras de cem sementes. Posteriormente, a massa média foi multiplicada por dez, obtendo-se dessa forma a massa de mil sementes. A média dos dados foi expressa em gramas.

\section{Composição química das sementes}

Teor de proteínas solúveis totais: determinado em amostras de $250 \mathrm{mg}$ de sementes secas e moídas (farinha). A extração foi feita utilizando-se $20 \mathrm{~mL}$ de $\mathrm{KH}_{2} \mathrm{PO}_{4} \mathrm{pH}$ 6,8, com posterior agitação e centrifugação a $3000 \mathrm{~g}$ por 15 minutos. Após coletar o sobrenadante, retirou-se uma alíquota de $0,1 \mathrm{~mL}$ do extrato e adicionaram-se 5,0 $\mathrm{mL}$ do reagente de cor (Comassie Blue). As proteínas solúveis totais foram determinadas espectrofotometricamente, conforme método descrito por BRADFORD (1976) e os resultados expressos em $\mu \mathrm{g} \mathrm{g}^{-1}$ de massa seca de semente.

Teor de açúcares solúveis totais: foi quantificado em 250 mg de sementes secas e moídas, homogeneizadas em $10 \mathrm{~mL}$ de etanol quente (85\%), com posterior agitação e centrifugação por 10 minutos a 3000 g. Os açúcares solúveis totais foram determinados pelo método da Antrona (CLEGG, 1956) e a leitura das amostras em espectrofotômetro no comprimento de onda de $620 \mathrm{~nm}$. Os resultados foram expressos em $\mu \mathrm{g} \mathrm{g}^{-1}$ de semente.

Teor de amido: foi quantificado em $250 \mathrm{mg}$ de sementes secas e moídas, homogeneizadas com $20 \mathrm{~mL}$ de $\mathrm{H}_{2} \mathrm{SO}_{4}$ a $0,2 \mathrm{~N}$, deixado por duas horas em banho-maria fervente. Logo após a centrifugação por 15 minutos a $3000 \mathrm{~g}$, foi coletado o sobrenadante e descartado o resíduo. A quantificação do amido foi feita pela reação com antrona, conforme método de McCREADY et al. (1950) e a leitura das amostras, em espectrofotômetro no comprimento de onda de $620 \mathrm{~nm}$. Os resultados foram expressos em $\mu \mathrm{g} \mathrm{g}^{-1}$ de semente.

Isoenzima alfa-amilase: foram utilizadas amostras de cotilédones retirados às 24 horas e aos sete dias após a semeadura. Utilizaram-se três repetições de aproximadamente de $250 \mathrm{mg}$ de cotilédone desestruturado com auxílio de grau e pistilo e colocados em tubo de microcentrífuga acrescidos de solução extratora composta pelo tampão do gel (Borato de Lítio 0,2 $\mathrm{M}$ à $\mathrm{pH} \mathrm{8,3+} \mathrm{Tris} \mathrm{Citrato} \mathrm{+} \mathrm{0,2} \mathrm{M}$ à $\mathrm{pH} 8,3$ ) $+0,15 \%$ de 2-mercaptoetanol) na proporção 1:2 (p/v). Realizou-se a eletroforese em géis de poliacrilamida $7 \%$, aplicando-se $20 \mu \mathrm{L}$ de cada amostra. Os géis foram colocados em cubas eletroforéticas mantidas em câmara fria com temperatura entre 4 e $6{ }^{\circ} \mathrm{C}$. Foram utilizados os sistemas de coloração descritos por Alfenas (1998). A interpretação dos resultados foi baseada na análise visual dos géis de eletroforese, levando em consideração a presença/ausência, e a intensidade de expressão de cada uma das bandas.

\section{Análise estatística}

O delineamento estatístico utilizado foi o inteiramente casualizado. Utilizou-se o Software WinStat (MACHADO e ConCEIÇão, 2003), sendo realizada análise de variância para todas as variáveis analisadas. As comparações múltiplas entre as médias foram feitas pelo teste $\mathrm{F}$ a $5 \%$ de probabilidade.

\section{RESULTADOS E DISCUSSÃO}

De acordo com os resultados dos testes de germinação e envelhecimento acelerado (Tabela 1), foi possível classificar os lotes de sementes de soja das três cultivares utilizadas nesse estudo, em lotes de alto e baixo vigor. A porcentagem de plântulas normais obtidas no teste de envelhecimento acelerado permaneceu, em média, $77 \%$ para os lotes debaixo vigor e $94 \%$ para os lotes de alto vigor. Resultados observados em vários estudos fazem com que o teste de envelhecimento acelerado seja reconhecido como um dos mais usuais para a avaliação do vigor de sementes de várias espécies, inclusive a soja, sendo capaz de proporcionar informações com alto grau de confiança (TEKRONY, 1995).

Com relação ao comprimento de plântulas (Tabela 2), pôde-se observar que lotes de sementes de alto vigor resultaram em plântulas de maior comprimento em relação a lotes de baixo vigor. Esses dados concordam com trabalhos realizados por VANZOLINI e CARVALHO (2002); esses pesquisadores verificaram que as sementes mais vigorosas produziram maior comprimento da raiz primária e comprimento total das plântulas.

No que se refere aos dados de produção de massa seca de plântulas (Tabela 2), os resultados permitem constatar que sementes vigorosas produzem plântulas com maiores quantidades de massa seca em relação a sementes de menor vigor. Em condições de campo, SchUCH et al. (1999) observaram que as sementes de alto vigor de aveia-preta produziram plantas com 
maiores produções de matéria seca, área foliar e taxas de crescimento, no período inicial da cultura. Em plantas de trigo sob condições não competitivas, KHAN et al. (1989) constataram que diferenças no vigor das sementes resultaram em diferenças na produção de matéria seca no período inicial de crescimento, as quais foram suficientes para resultar em maior rendimento final de grãos. Em trabalho desenvolvido por Hofs et al. (2004), com sementes de arroz irrigado, constata-se que a utilização de sementes de elevada qualidade fisiológica promove aumento de rendimento próximo a 10\%, ao passo que, o uso de sementes de baixo vigor levou à desuniformidade na maturação e redução na massa de mil sementes.

Quanto aos dados de massa seca dos cotilédones obtidos aos sete dias após a semeadura (Tabela 2), com exceção da cultivar BRS 246RR, os valores obtidos em sementes de baixo vigor e com menor massa de mil sementes não diferiram dos valores obtidos em sementes de alto vigor, o que demonstra a ocorrência de uma maior velocidade na mobilização das reservas em sementes mais vigorosas. Esses dados corroboram com resultados verificados por CORTE et al. (2006); segundo esses pesquisadores, a massa seca dos cotilédones revela correlação positiva com os teores de lipídios, amido, proteínas e de carboidratos. O consumo das reservas energéticas dos cotilédones foi fortemente correlacionado com a redução na massa seca destes $\mathrm{e}$, inversamente correlacionado com o aumento na produção de biomassa das plântulas. Essas relações evidenciam a mobilização dos compostos de reserva dos cotilédones (fonte) e sua translocação para outros órgãos (dreno), à medida que a redução na massa seca cotiledonar reflete o aumento na produção de biomassa de parte aérea e raiz da nova plântula (CORTE et al., 2006). Esse processo ocorre porque a germinação da semente é iniciada graças às reservas próprias do embrião e depois mantida com o consumo dos componentes dos tecidos de reserva, pela atividade enzimática e pelo fluxo dos componentes solúveis às regiões de crescimento onde há rápido consumo (CARVALHO e NAKAGAWA, 2000).

Com relação à massa de mil sementes observase que sementes mais vigorosas têm maiores valores em comparação às sementes de menor vigor (Tabela 2). Diferenças no vigor associadas com as características das

Tabela 1. Qualidade fisiológica de sementes de soja de três cultivares, provenientes de lotes com alto e baixo vigor

\begin{tabular}{lccc}
\hline Cultivar & Nível de Vigor & Germinação & Envelhecimento Acelerado \\
\hline \multirow{2}{*}{219 RR } & & $98 \mathrm{a}$ & $96 \mathrm{a}$ \\
& Alto & $82 \mathrm{~b}$ & $76 \mathrm{~b}$ \\
\hline CV & Baixo & 3,98 & 4,68 \\
$246 \mathrm{RR}$ & & $92 \mathrm{a}$ & $92 \mathrm{a}$ \\
\hline CV & Alto & $82 \mathrm{~b}$ & $74 \mathrm{~b}$ \\
\hline $243 R R$ & Baixo & 6,63 & 5,78 \\
\hline CV & & $94 \mathrm{~ns}$ & $94 \mathrm{a}$ \\
\hline
\end{tabular}

Letras que diferem na coluna dentro de cada cultivar, indicam diferença significativa pelo teste $\mathrm{F}$ a $5 \%$ de probabilidade de erro.

Tabela 2. Valores de massa de mil sementes (PMS), massa seca de cotilédones (MSC), massa seca de plântulas (MSP) e comprimento de plântulas $(\mathrm{CP})$ aos oito dias após a semeadura de três cultivares de soja, provenientes de lotes com alto e baixo vigor

\begin{tabular}{|c|c|c|c|c|c|}
\hline Cultivar & Nível de Vigor & PMS & MSC & MSP & $\mathrm{CP}$ \\
\hline \multirow{3}{*}{ 219RR } & & $\mathrm{g}$ & - & - & $\mathrm{mm}$ \\
\hline & Alto & $135 \mathrm{a}$ & $47,59 \mathrm{~ns}$ & $54,32 \mathrm{a}$ & $28,86 \mathrm{a}$ \\
\hline & Baixo & $117 \mathrm{~b}$ & $45,21 \mathrm{~ns}$ & $45,90 \mathrm{~b}$ & $21,74 \mathrm{~b}$ \\
\hline $\mathrm{CV}$ & & 2,24 & 19,06 & 4,17 & 4,50 \\
\hline \multirow{2}{*}{ 246RR } & Alto & $160 \mathrm{a}$ & $98,11 \mathrm{a}$ & $43,22 \mathrm{a}$ & $21,03 \mathrm{a}$ \\
\hline & Baixo & $149 \mathrm{~b}$ & $76,11 \mathrm{~b}$ & $36,94 \mathrm{~b}$ & $15,29 \mathrm{~b}$ \\
\hline $\mathrm{CV}$ & & 2,02 & 10,73 & 7,64 & 8,25 \\
\hline \multirow{2}{*}{ 243RR } & Alto & $112 \mathrm{a}$ & $46,11 \mathrm{~ns}$ & $42,22 \mathrm{a}$ & $25,90 \mathrm{a}$ \\
\hline & Baixo & $103 \mathrm{~b}$ & $51,22 \mathrm{~ns}$ & $35,11 \mathrm{~b}$ & $19,54 \mathrm{~b}$ \\
\hline $\mathrm{CV}$ & & 1,98 & 12,05 & 8,60 & 9,51 \\
\hline
\end{tabular}

Letras que diferem na coluna dentro de cada cultivar, indicam diferença significativa pelo teste F a 5\% de probabilidade de erro. 
sementes são geralmente atribuídas à composição química, principalmente com relação à quantidade de reservas ou a deficiência no metabolismo (HAMPTON, 1973). Quanto maior o teor de reservas das sementes, maior será o vigor das plântulas originadas, assim, o suprimento de água durante o período de desenvolvimento da semente pode influenciar indiretamente seu vigor pelo efeito que exerce sobre a composição química (CARVALHO e NAKAGAWA, 2000).

No que se refere aos conteúdos de proteínas solúveis (Tabela 3), sementes mais vigorosas proporcionaram maiores quantidades em relação às de menor vigor. Conforme trabalhos desenvolvidos por outros pesquisadores, o conteúdo de proteína da semente está relacionado com a qualidade fisiológica destas, e além dos fatores genéticos, os teores de óleo e proteínas das sementes de soja também são fortemente influenciados pelo ambiente, principalmente durante o período de enchimento (WILCOx e CAVINES, 1992; RAO et al., 1993). Segundo Marcos FilHo (2005), durante o processo de deterioração de sementes ocorre decréscimo do teor e da síntese de proteínas, acréscimo do teor de aminoácidos, decréscimo do conteúdo de proteínas solúveis e desnaturação provocada por temperaturas altas. Em trabalho realizado com sementes de arroz, constatou-se que o teor de proteína bruta na semente é capaz de diferenciar lotes de arroz com variações nos níveis de vigor, e correlacionar-se com a emergência em campo, quando esta ocorre em condições desfavoráveis (BortolotTo et al., 2008).

Com relação à quantidade de açúcares presentes nas sementes, observou-se que os conteúdos de amido e de açúcar solúvel foram maiores em sementes mais vigorosas (Tabela 3). Segundo CORTE et al. (2006), a grande quantidade de carboidratos solúveis observada em sementes de Caesalpinia peltophoroides resulta não só no fornecimento de energia para a germinação, mas também confere maior armazenabilidade a essas sementes. Além disso, resultados constatados por BUCKERIDGE et al. (1992), em sementes de Copaifera langsdorfii, indicam que ocorre redução no conteúdo de açúcares solúveis durante e após a germinação, ressaltando a importância da mobilização dessas reservas da semente durante o desempenho inicial das plântulas.

Na análise da isoenzima alfa amilase (Figuras 1a,b), nãoforamevidenciadas diferenças nopadrãodeexpressão dessa enzima em nenhuma das épocas avaliadas. A alfaamilase, enzima hidrolítica, causa a conversão de amido em açúcares, utilizados no crescimento do embrião (ARTECA, 1995). Os resultados desse trabalho discordam

Tabela 3. Composição química de sementes de soja de três cultivares, provenientes de lotes com alto e baixo vigor

\begin{tabular}{|c|c|c|c|c|}
\hline Cultivar & Nível de Vigor & Amido & Açúcar Solúvel & Proteína Solúvel \\
\hline \multirow{3}{*}{ 219RR } & & & $-\mu \mathrm{g} \mathrm{g}^{-1}$ & \\
\hline & Alto & $49 \mathrm{a}$ & $8 \mathrm{~ns}$ & $21 \mathrm{a}$ \\
\hline & Baixo & $40 \mathrm{~b}$ & $7 \mathrm{~ns}$ & $18 \mathrm{~b}$ \\
\hline $\mathrm{CV}$ & & 23,63 & 15,08 & 11,52 \\
\hline \multirow{2}{*}{ 246RR } & Alto & $16 \mathrm{~ns}$ & $10 \mathrm{a}$ & $19 \mathrm{a}$ \\
\hline & Baixo & $15 \mathrm{~ns}$ & $6 \mathrm{~b}$ & $15 \mathrm{~b}$ \\
\hline $\mathrm{CV}$ & & 12,66 & 12,64 & 12,33 \\
\hline \multirow{2}{*}{ 243RR } & Alto & $53 \mathrm{a}$ & $12 \mathrm{a}$ & $20 \mathrm{a}$ \\
\hline & Baixo & $38 \mathrm{~b}$ & $11 \mathrm{~b}$ & $18 \mathrm{~b}$ \\
\hline $\mathrm{CV}$ & & 6,88 & 8,83 & 9,56 \\
\hline
\end{tabular}

Letras que diferem na coluna dentro de cada cultivar, indicam diferença significativa pelo teste $\mathrm{F}$ a 5\% de probabilidade de erro.
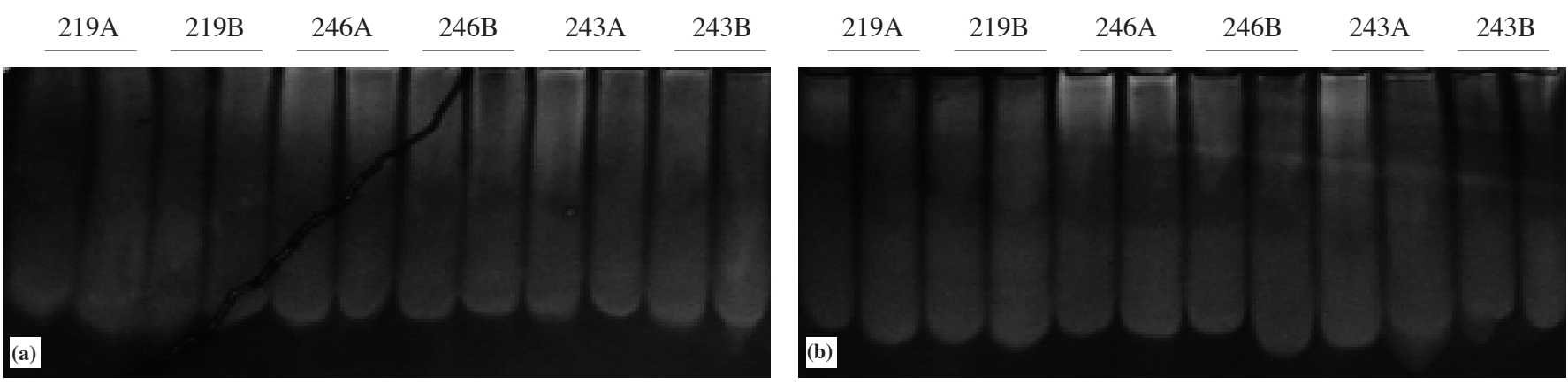

Figura 1. Isoenzima alfa amilase em cotilédones de sementes soja de diferentes cultivares, em lotes de alto e baixo vigor: 219A (CD 219RR alto); 219B (CD 219RR baixo); 246A (BRS 246RR alto); 246B (BRS 246RR baixo); 243A (BRS 243RR alto); 243B (BRS 243RR baixo); em a: 24 horas após a semeadura; em b: 7 dias após a semeadura. 
dados verificados por outros autores, os quais afirmam que no processo de deterioração das sementes várias enzimas, tais como, lipases, amilases, proteinases, desidrogenases e fosfatases reduzem sua atividade em decorrência do decréscimo na qualidade fisiológica das sementes, (BEWLEY e BLACK, 1994). As mudanças na atividade enzimática estão embasadas na suscetibilidade específica destas enzimas ao agente causador do estresse ou, estas alterações são resultados de um único evento, por exemplo, ativação de proteases, as quais afetariam a função de várias enzimas (VIEIRA et al., 2000).

\section{CONCLUSÃO}

De acordo com os resultados deste trabalho, sementes de soja de alto vigor possuem maiores teores de proteínas solúveis, amido e açúcares solúveis, e maior capacidade de mobilização de reservas na germinação, resultando em plântulas de soja com melhor desempenho inicial.

\section{AGRADECIMENTOS}

Os autores agradecem à CAPES (Coordenação de Aperfeiçoamento de Pessoal de Nível Superior), ao $\mathrm{CNPq}$ (Conselho Nacional de Desenvolvimento Científico e Tecnológico) e à FAPERGS (Fundação de Amparo à Pesquisa do Rio Grande do Sul), pelo apoio financeiro concedido aos autores em diversas instâncias durante o desenvolvimento deste trabalho.

\section{REFERÊNCIAS}

ALFENAS, A.C. Eletroforese de isoenzimas e proteínas afins. Viçosa: UFV, 1998. 574p.

ARTECA, R.N. Plant growth substances: principles and applications. Pennsylvania State University: Chapman e Hall, 1995. 332p.

AOSA - Association of Official Seed Analysts -. Seed vigor testing handbook. East Lansing. 1983. 88p. (Contribution, 32)

BEWLEY, J.D.; BLACK, M. Physiology of development and germination. New York: Plenum Press, 1994. 445p.

BORTOLOTTO, R.P.; MENEZES, N.L.; GARCIA, D.C.; MATTIONI, N.M. Teor de proteína e qualidade fisiológica de sementes de arroz. Bragantia, v.67, p.513-520, 2008.

BRADFORD, M.M. A rapid and sensitive method for the quantification of microgram quantities of protein utilizing the principle of protein-dye binding. Analytical Biochemistry, v.72, p.248-254, 1976.

BRASIL. Ministério da Agricultura e Abastecimento e de Reforma Agrária. Regras para análise de sementes. Brasília: SNDA/DNDV / CLAV, 1992. 365p.
BUCKERIDGE, M.S.; ROCHA, D.C.; REID, J.S.G.; DIETRICH, S.M.C. Xyloglucan structure and post-germinative metabolism in seeds of copaifera langsdorffii from savanna and forest populations. Physiologia Plantarum, v.86, p.145-151, 1992.

BUCKERIDGE, M.S.; PANEGASSI, V.R.; DIETRICH, S.M.C. Storage carbohydrate mobilization in seeds of Dimorphandra mollis Benth.(Leguminosae) following germination. Revista Brasileira de Botânica, v.18, p.171-175, 1995.

CARVALHO, N.M.; NAKAGAWA, J. Sementes: ciência, tecnologia e produção. 4.ed. Jaboticabal: FUNEP, 2000. 588p.

CLEGG, K.M. The application of the anthrone reagent to the estimation of starch in cereals. Journal of the Science of Food and Agricultural, v.3, p.40-44, 1956.

CORTE, V.B.; BORGES, E.E.L; PONTES, C.A.; LEITE, I.T.A.; VENTRELLA, M.C.; MATHIAS, A.A. Mobilização de reservas durante a germinação das sementes e crescimento das plântulas de Caesalpinia peltophoroides Benth. (LeguminosaeCaesalpinoideae). Revista Árvore, v.30, p.941-949, 2006.

HAMPTON, J.G. Vigour testing within laboratories of the International Seed Testing Association: a survey. Seed Science and Technology, v.20, p.427-452, 1973.

HOFS, A.; SCHUCH, L.O.B.; PESKE, S.T.; BARROS, A.C.S.A. Efeito da qualidade fisiológica das sementes e da densidade de semeadura sobre o rendimento de grãos e qualidade industrial de arroz. Revista Brasileira de Sementes, v.26, p.55-62, 2004.

KHAN, E.M.; ROBERTS, E.H.; ELLIS, R.H. Effects of seed ageing on growth and yield of spring wheat at different plant population densities. Field Crops Research, v.20, p.175-190, 1989.

KRZYZANOWSKI, F.C.; VIEIRA R.D.; FRANÇA NETO J.B. Vigor de sementes: conceitos e testes. Londrina: ABRATES, 1999. 218p.

MACHADO, A.A.; CONCEIÇÃO, A.R. Sistema de análise estatística para Windows. WinStat. Versão 2.0. UFPel. 2003.

MARCOS FILHO, J. Fisiologia de sementes de plantas cultivadas. Piracicaba: FEALQ, 2005. 495p.

McCREADY, R.M.; GUGGOLZ, J.; WENS, H.S. Determination of starch and amylases in vegetables. Analytical Chemistry, v.22, p.1156-1158, 1950.

MELO, P.T.B.S.; SCHUCH, L.O.B.; ASSIS, F.N.; CONCENÇO, G. Comportamento individual de plantas originadas de sementes com diferentes níveis de qualidade fisiológica em populações de arroz irrigado. Revista Brasileira de Sementes, v.28, p.84-94, 2006.

NAKAGAWA, J. Testes de vigor baseados no desempenho das plântulas. In: KRZYZANOWSKI, F.C.; VIEIRA, R.D.; FRANÇA NETO, J.B. (Ed.). Vigor de sementes: conceitos e testes. Londrina: ABRATES, 1999. cap.2, p.2-24. 
RAO, A.C.S.; SMITH, J.L.; JANDHJYALA, V.K.; PAPENDICK, R.I.; PARR, J.F. Cultivar and climatic effects on the protein content of soft white winter wheat. Agronomy Journal, v.85, p.123-128, 1993.

SCHUCH, L.O.B.; NEDEL, J.L; MAIA, M.S.; ASSIS, F.N. Vigor de sementes e adubação nitrogenada em aveia-preta (Avena strigosa Schreb.). Revista Brasileira de Sementes, v.21, p.127134, 1999.

SCHUCH, L.O.B.; NEDEL, J.L; MAIA, M.S.; ASSIS, F.N. de. Vigor de sementes e análise de crescimento de aveia-preta. Scientia Agricola, v.57, p.305-312, 2000.

SIDDIQUE, K.H.M.; TENNAT, D.; PERRY, M.W.; BELFORD, R.K. Water use and water use efficiency of old and modern wheat cultivars in a mediterranean-type environment. Australian Journal of Agricultural Research, v.41, p.431-447, 1990.
TEKRONY, M.A.S. Accelerated ageing. In: HAMPTON, J.G.; TEKRONY, D.M. (Ed.). Handbook of vigour test methods. 1995. p.35-50.

VANZOLINI, S.; CARVALHO, N.M. Efeito do vigor de sementes de soja sobre o seu desempenho em campo. Revista Brasileira de Sementes, v.24, p.33-41, 2002.

VIEIRA, A.R.; VIEIRA, M.G.G.C.; OLIVEIRA, J.A.; SANTOS, C.D. Alterações fisiológicas e enzimáticas em sementes dormentes de arroz armazenadas em diferentes ambientes. Revista Brasileira de Sementes, v.22, p.53-61, 2000.

WILCOX, J.R.; CAVINES, J.F. Normal and low lenolenic acid soybean strains. Response to planting date. Crop Science, v.32, p.1248-1251, 1992.

ZIEGLER, P. Carbohydrate degradation during germination. In: KIGEL, J.; GALILI, G. (Ed.). Seed development and germination. New York: Marcel Dekker, 1995. p.447-474. 